\title{
DESINDUSTRIALIZAÇÃO E MUNDANÇA ESTRUTURAL NA REGIÃO SUDESTE: UM ESTUDO COMPARADO
}

\author{
Wallace Marcelino Pereira ${ }^{1}$ \\ Silvio Antonio Ferraz Cario ${ }^{2}$
}

Resumo: O presente trabalho tem por objetivo avaliar as especificidades da mudança estrutural em três estados da região Sudeste - São Paulo, Rio de Janeiro e Minas Gerais - visando contribuir para o debate sobre a desindustrialização no Brasil entre os anos de 1996 e 2013. Para tanto, resgata-se os estudos empírico-analíticos acerca da mudança estrutural na indústria brasileira. Utilizou-se indicadores tradicionais de estudo sobre desindustrialização para os estados federativos selecionados por intensidade tecnológica, e contribui na literatura sobre o tema, ao utilizar o Índice de Desindustrialização Relativa Regional - DRR, visando mitigar os problemas relacionados à variação do câmbio que afetam a razão VTI/VBPI. Constatou-se a existência de um processo de desindustrialização relativa com impactos distintos na estrutura industrial de cada estado analisado. Apesar disso, os estados de São Paulo, Rio de Janeiro e Minas Gerais têm avançado, em níveis diferenciados, ainda que lentamente, de uma indústria de baixa intensidade tecnológica para uma indústria de média baixa e média alta intensidade tecnológica.

Palavras chave: Desindustrialização - Economia regional - Mudança Estrutural - Indústria Desenvolvimento Regional

\begin{abstract}
This paper aims to assess the specific structural change in three states in the Southeast - São Paulo, Rio de Janeiro and Minas Gerais - to contribute to the debate on de-industrialization in Brazil between 1996 and 2013. Therefore, rescues to the empirical-analytic studies of structural change in the Brazilian industry. We used traditional indicators study on de-industrialization to the federal states selected by technological intensity, and contributes to the literature on the subject, using the Deindustrialization Index Relative Regional - DRR, to mitigate the exchange rate variation related issues affecting the reason VTI / VBPI. It was found that there is a process of relative de-industrialization with different impacts on the industrial structure of the analyzed state. Nevertheless, the states of São Paulo, Rio de Janeiro and Minas Gerais have advanced at different levels, albeit slowly, in a low technology industry to an average low of industry and medium-high technological intensity.
\end{abstract}

Keywords: Deindustrialization - Regional Economy - Structural Change - Manufacturing Regional Development

Área 4: Economias regionais e urbanas

JEL: R1

\footnotetext{
${ }^{1}$ Doutorando em Economia pelo CEDEPLAR/UFMG. Contato: wallacemp2000@yahoo.com.br

${ }^{2}$ Prof. Dr. em Economia do DERI/PPGECO/UFSC. Contato: fecario@yahoo.com.br
} 


\section{Introdução}

A economia brasileira a partir de meados da década de 80 começou a apresentar contínua queda da participação da indústria na formação do Produto Interno Bruto (PIB). Esse fenômeno tem chamado a atenção de diversos pesquisadores para a existência de um processo denominado desindustrialização relativa (COMIN, 2009; SILVA, 2012). Diante disso, um intenso debate tem sido empreendido, na medida em a indústria de transformação é o motor do crescimento por meio de seus retornos crescentes de escala, impacto positivo sobre a taxa de produtividade da economia, bem como sua capacidade em promover transformações estruturais nos países subdesenvolvidos (KALDOR, 1966; THIRWALL, 2002; FURTADO, 1961).

Apesar disso, pouca atenção tem sido dada à dimensão regional do processo de desindustrialização, e seu impacto em termos da mudança estrutural na economia brasileira. A literatura apresenta escassos estudos muito embora tenham apontado para a existência de um processo de desindustrialização relativa, com a peculiaridade dos estados federativos analisados estarem se comportando de formas distintas. Em outros termos, de evolução do processo de desindustrialização apresenta grau e extensão diferenciada entre os estados federativos. Dessa forma, torna-se relevante avaliar a tese da desindustrialização a partir de uma abordagem regional, pelo fato de que não só torna-se possível compreender as especificidades de cada região, como também abre-se espaço para esboçar possíveis soluções adequadas à cada realidade econômica.

Neste sentido, o propósito deste estudo é analisar individualmente, a partir de indicadores o processo de desindustrialização nos estados da região Sudeste do Brasil: São Paulo, Rio de Janeiro, e Minas Gerais, considerados a $1^{\mathrm{a}}$., $2^{\mathrm{a}}$. e $3^{\mathrm{a}}$. economias do país, respetivamente, congregando pouco mais de 56\% do PIB brasileiro em 2013. A indústria vem perdendo participação nestas unidades federativos, requerendo portanto, estudo no propósito de melhor caracterizar tal processo, a partir de uma abordagem por intensidade tecnológica.

Para tanto, o presente artigo está dividido em 9 partes incluindo esta introdução. Na segunda parte discute-se as teorias relacionadas à desindustrialização, na terceira parte aborda-se a questão metodológica e a apresentação das variáveis discutidas no presente trabalho, e na quarta parte traça-se um panorama da região Sudeste. Na quinta, sexta e sétima parte analisa-se o comportamento da indústria dos estados de São Paulo, Rio de Janeiro e Minas Gerais. Na oitava parte é apresentada uma síntese dos indicadores analisados, e na nona parte é apresentada as considerações finais.

\section{Aspecto analítico sobre a desindustrialização no Brasil: síntese do debate}

O fenômeno denominado desindustrialização foi constatado pela primeira vez por volta da década de 70, nos países desenvolvidos, quando a indústria começou a apresentar queda continuada de sua participação na composição do PIB. Até então, esse comportamento não havia suscitado grande debate, até que com a divulgação do relatório da United Nations Conference on Trade and Development (UNCTAD, 2003) a atenção de diversos pesquisadores passou a se concentrar no esforço em conceituar, entender a origem e as causas desse processo em curso nos países desenvolvidos.

O resultado desse esforço de compreensão acerca do fenômeno desindustrialização resultou, como aponta Morceiro (2012), na existência de três eixos que devem ser observados quando se trata do referido processo, a sabe: 1) queda do emprego (em termos absolutos e/ou em relação ao emprego total da nação); 2) queda da produção (em termos absolutos e/ou em relação ao PIB do país); e 3) deterioração do balanço de pagamentos, especialmente a deterioração do saldo comercial da indústria de transformação.

A partir desses eixos, autores como Rowthorn e Coutts, (2004); Rowthorn e Ramaswamy, (1999); Bazen e Thirlwall,(1989) concentram esforços no entendimento do comportamento do emprego, em função de sua importância na geração de renda e na produtividade na indústria. Na mesma linha de pensamento dos referidos autores, Palma (2005; 2008) considera que a desindustrialização ocorre em duas fases, sendo a primeira marcada pela queda em termos relativos do emprego industrial, e em uma segunda fase, em termos absolutos com a ascensão do setor de serviços como o principal absorvedor de mão de obra. 
Por outro lado, Tregenna (2009) coloca que a desindustrialização é um fenômeno em que não só o emprego industrial, mas também o valor adicionado da indústria se reduzem em relação ao emprego total e do PIB, respectivamente. Assim, diante dessa definição abrangente Oreiro e Feijó (2010) expõem que "uma economia não se desindustrializa quando a produção industrial está estagnada ou em queda, mas quando o setor industrial perde importância como fonte geradora de empregos e/ ou de valor adicionado para uma determinada economia” (OREIRO e FEIJO, 2010, pg 221).

Outro eixo que mereceu atenção especial trata do balanço de pagamentos ou do comércio internacional. Nesta perspectiva, o emprego a produção não são considerados os elementos mais importantes para se analisa a desindustrialização. Para autores como Singh, (1977); Cairncross, (1978); Blackaby, (1978) a diminuição da participação do emprego manufatureiro na economia total pode ser desejada caso venha a ser acompanhada de aumentos na produtividade da economia. A desindustrialização torna-se um problema somente quando ocorre fragilidade na capacidade do país em pagar suas importações, significando aumento da restrição ao crescimento econômico.

No que se refere à literatura brasileira, a abordagem heterodoxa aponta a existência de desindustrialização relativa, conforme se observa nos estudos de Comin (2009) e Silva (2012). Do ponto de vista da heterodoxia, este processo iniciou-se na década de 80, cuja razão reside na crise econômica decorrente da exaustão do padrão de financiamento externo e da fragilidade fiscal do Estado. Este ao perder capacidade em estimular a economia, afetou a evolução da indústria em um contexto de mudança do paradigma tecno-produtivo mundial. Naquele contexto, a crise da dívida externa levou à formulação de uma política econômica com o objetivo de alcançar superávits comerciais visando enfrentar a retração das fontes externas de financiamento, implicando necessariamente à contenção de importações e o incentivo às exportações (LAPLANE e SARTI, 2006). Além disso, o Estado foi perdendo a capacidade de induzir e coordenar investimentos empresariais privados, levando à deterioração tanto da infraestrutura física, quanto da infraestrutura em ciência e tecnologia (C\&T) (SARTI e HIRATUKA, 2011).

No esteio do processo de desindustrialização em curso, na década de 90 inicia-se o processo de abertura do mercado associadas à iniciativas de desregulamentação econômica e privatização de empresas estatais. A concorrência passou a ser o elemento central e responsável pelo crescimento da economia dentro na nova política econômica estabelecida. Nesse sentido, observou-se a contínua perda de capacidade de financiamento e investimento por parte das empresas públicas. Concomitantemente, observou-se o arrefecimento da capacitação tecnológica do setor privado que se enfraqueceu pela ausência de demanda, e pelo fim dos estímulos induzidos pelo Estado ao requer o cumprimento das normas, padrões técnicos e de qualidade quando da aquisição de equipamentos e serviços (FERRAZ et al, 1995).

Assim, os 2000 são marcados por uma configuração industrial caracterizada pela tendência à incapacidade em incorporar a nova onda tecnológica, ao passo que as indústrias baseadas em recursos minerais passaram a ganhar cada vez mais espaço (CARNEIRO, 2008). Os ajustes da indústria nacional ao longo de vários anos fez com que o investimento em inovação fosse perdendo fôlego, ao mesmo tempo em que a reduzida exposição à concorrência externa abriu espaço para o incentivo à especialização em atividades intensivas em recursos naturais, levando o Brasil a um processo de "especialização regressiva" da produção industrial (LAPLANE e SARTI, 2006).

No quadro da política econômica liberalizante, Bresser e Marconi (2008) apontam que o processo de abertura comercial e financeira eliminou mecanismos - política de controles tarifários, alfandegários e cambiais - até então capazes de neutralizar a “doença holandesa” que já ameaçava a economia brasileira. Isso se deve ao fato de que, como o Brasil tem vantagens comparativas na produção de diversas commodities, a "doença holandesa" começou a se manifestar de modo lento e gradativo, sendo que uma das formas de expressão se dá pela apreciação artificial do câmbio em função da abundância dos recursos naturais exportados. Esse comportamento cambial, se por um lado facilitou a entrada significativa de divisas internacionais, por outro provocou consequências nefastas para a estrutura industrial, ou em outros termos, a desindustrialização (Bresser Pereira, 2005). A manutenção desse regime cambial, tem inviabilizado investimentos produtivos em setores industriais de bens comercializáveis, que incorporam tecnologia no estado das artes, além de esgarçar elos da cadeia produtiva interna pelo incentivo dado às aquisições de mercadorias, insumos e equipamentos no mercado externo. 
Mas para além da questão externa, Loures et all, (2006) ao investigar a desindustrialização a partir de uma perspectiva de política econômica, constatou que desde 1994 a política econômica caracteriza-se pelo que se pode chamar de "servidão consentida". Esse conceito refere-se a uma combinação perversa de juros altos, taxa de câmbio apreciada, alta taxa de tributação, e redução do gasto público em infraestrutura. A partir desse conceito constata-se que a condução da política econômica, nestes termos, tem contribuído para ocorrência de queda do nível de produtividade, e da competitividade das exportações manufatureiras, cujo resultado tem colaborado para o processo de desindustrialização em curso.

Por outro lado, a vertente ortodoxa coloca que o processo de desindustrialização no Brasil, tem sua origem no processo de ajustamento porque vem passando o mercado. Nessa perspectiva, a indústria brasileira está inserida no movimento global de países, no sentido de convergir para o nível ideal de desenvolvimento industrial (BONELLI, PESSÔA e MATOS, 2013). Essa constatação foi obtida a partir da avaliação de 170 países em um período de 40 anos, no qual identificaram que o Brasil sofre de "doença soviética”, entendida como uma indústria muito acima do padrão internacional quando se considera o grau de desenvolvimento, população, tecnologia, dotação de recursos naturais. A partir desse conceito, a desindustrialização não seria um problema, uma vez que a indústria brasileira participava no PIB em um nível muito acima do nível previsto para o seu padrão enquanto país em desenvolvimento, e mais que isso, a liberalização econômica, seria responsável por fazer a participação da indústria no PIB voltar ao ponto de normalidade condizente com a condição brasileira.

Em estudo de Feijó e Oliveira (2013), detecta-se que o processo de desenvolvimento adotado nos últimos vinte anos foi o responsável por: $1^{\circ}$.) uma manufatura menos densa em termos de elos da cadeias produtivas, induzindo que parte dos estímulos de demanda agregada sejam transferidos para o exterior, em função de parte da oferta ser atendida por bens e serviços importados, e; 2) enfraquecimento das ligações dos setores industriais - tanto a montante, quanto a jusante - em relação aos demais setores da economia, limitando o dinamismo industrial.

Fato é que, enquanto o Brasil apresenta uma trajetória oscilante com viés marcado pela deterioração de sua indústria, a Ásia, por meio da China, empreendeu esforços no sentido de capturar parte das manufaturas da Europa e dos Estados Unidos como forma de alavancar seu desenvolvimento industrial. Essa estratégia envolveu parcerias entre capital estrangeiro e capital nacional privado ou estatal perpassando por etapas mais simples, até as etapas mais complexas. Associado a esse comportamento asiático, mais tarde, em resposta a crise econômica pós 2008, os países desenvolvidos passaram internamente a reestruturar seu parque industrial, e a adotar políticas de comércio mais agressivas para exportar seus produtos, em face da capacidade ociosa interna, levando os países em desenvolvimento, e em particular o Brasil a apresentar dificuldades no comercio internacional de bens manufaturados (SARTI e HIRATUKA, 2011).

Ainda, no que tange à posição relativa brasileira no plano internacional, Arend (2014) aponta a existência de relativa rigidez e heterogeneidade na estrutura industrial brasileira, e que sob essas condições, a tendência à especialização produtiva será a tônica na economia nacional. O argumento é que até 1980, a estrutura industrial do país seguiu em linha com o padrão produtivo mundial, marcado pelo movimento internacional de capital posto pela $4^{\mathrm{a}}$. revolução tecnológica, conforme apontou Peres (2004). Nesse movimento delineou-se para o Brasil um processo de catching up, mas a partir de 80 até os dias atuais, a estrutura industrial adentrou em um processo de fall behind, caracterizado reduzido dinamismo industrial em relação à economia mundial. Ainda segundo o referido autor, esse comportamento coincide, no plano interno, com o fim de políticas industriais, liberalização comercial e financeira e sobrevalorização cambial. Além disso, no plano externo, a nova revolução tecnológica e industrial, levou uma nova geografia industrial marcada por novas formas globais de produção e comercialização de mercadorias. 


\section{Notas metodológicas}

O referido estudo objetiva avaliar as especificidades da mudança estrutural da região Sudeste ${ }^{3}$ visando contribuir para o debate da desindustrialização no Brasil no período de 1996 a 2013. Para tanto, o método de abordagem a ser utilizado, é de caráter histórico dedutivo, dado que se parte da realidade e da observação desta para a realização da análise. As variáveis industriais correspondem aos dados da Indústria de Transformação disponibilizados pela Pesquisa Industrial Anual - PIA/IBGE. Utilizou-se o Valor Bruto da Produção Industrial $-\mathrm{VBPI}^{4}$, Valor da Transformação Industrial - VTI ${ }^{5}$. Os dados referentes ao Pessoal Ocupado, expressam o número de pessoas que se encontram trabalhando nas unidades industriais, e foram extraídos da RAIS/MTE.

Foi construído o indicador tradicional de análise do comportamento industrial, a saber: a razão entre VTI e VBPI (VTI/VBPI) que expressa a proporção de valor agregado transformada pela indústria. Em outros termos, a razão (VTI/VBPI) é considerada uma proxy da densidade do tecido industrial, de modo que, quanto mais próxima de um, mais a produção é intensiva em valor agregado gerado no próprio país.

Entretanto, como aponta Torres e Silva (2015), a razão VTI/VBPI é muito sensível a variações cambiais, além de não captar as diferenças intersetoriais, razão pela qual utiliza-se o indicador adaptado de Arend (2014) proposto por Pereira (2016) denominado Índice de Desindustrialização Relativa Regional - DRR, que pode ser expresso como:

$$
D R R_{t(U F \text { ou região })}=I V I_{t(U F \text { ou região })} / I V I_{t(\text { Brasil })}
$$

Onde:

$$
I V I_{t, t+n}=\left(V B P I_{t+n} / V B P I_{t}\right) * 100
$$

Ou seja trata-se da razão do Valor Bruto da Produção Industrial entre um período t e um período $t+n{ }^{6}$

Desta forma, o DRR objetiva mostrar o desempenho industrial relativo de determinada região em relação ao país ou região de referência. Em outros termos, um valor menor que 1 indica que a região está apresentando uma taxa de crescimento do produto manufatureiro menor que o país ou região de referência, o que caracteriza um processo de desindustrialização relativa. Um valor de DRR igual a 1 significa que a taxa de crescimento do VBPI é a mesma entre os dois países, e por sua vez, não está ocorrendo perda ou ganho relativo. Por fim, um DRR maior que 1 significa que a região está apresentando uma taxa de crescimento do produto manufatureiro maior que o país ou região de referência, sugerindo a existência de um processo de industrialização relativa.

Todos dos dados foram deflacionados pelo IPA-OG da Fundação Getúlio Vargas, tendo como ano base 2013.

\section{A região Sudeste do Brasil: comportamento industrial}

O Sudeste é a região economicamente mais importante do Brasil, onde os estados de São Paulo, Rio de Janeiro, Minas Gerais e Espírito Santo, considerados a $1^{\mathrm{a}}$.; $2^{\mathrm{a}}$.; $3^{\mathrm{a}}$ e $4^{\mathrm{a}}$ economias em tamanho do PIB, respectivamente, veem passando por um processo lento de transformação de sua economia. Conforme aponta a Tabela 01, entre 1996 e 2013, apenas o estado de São Paulo apresentou perda

\footnotetext{
${ }^{3} \mathrm{O}$ estado do Espírito Santo não foi analisado na quinta parte devido a impossibilidade de desagregação metodológica, o que poderia prejudicar a análise.

${ }^{4}$ O VBPI corresponde ao conceito de valor das expedições industriais, a saber: o valor das vendas de produtos fabricados e serviços industriais prestados pela unidade local, acrescido do valor das transferências dos produtos fabricados para venda em outras unidades locais (IBGE, 2011).

${ }^{5}$ O Valor da Transformação Industrial (VTI), que segundo o IBGE (2011), corresponde à diferença entre o Valor Bruto da Produção Industrial (VBPI), e o Custo das Operações Industriais (consumo de matérias-primas, materiais auxiliares e componentes somados à variável outros custos de operação industrial) (COI), calculados ao nível das unidades locais produtivas industriais.

${ }^{6}$ Para mais detalhes ver Pereira (2016).
} 
sistemática de sua participação no valor adicionado nacional, ao passo que, Minas Gerais e o Espirito Santo apresentaram ligeiro crescimento. Esses comportamentos, associados à estagnação da participação do valor adicionado do Rio de Janeiro em relação ao valor adicionado nacional, resultou na queda da participação do Sudeste no referido valor adicionado nacional, evidenciando o peso que a economia paulista possui na região a ponto de influenciar negativamente, no conjunto, quando de sua queda.

Tal quadro se torna evidente quando observa-se o comportamento da indústria (extrativa, de transformação e construção civil) cujo comportamento ao longo do período analisado foi bastante peculiar. Considerando o valor adicionado da indústria em geral em relação ao valor adicionado nacional, percebe-se que somente o estado de São Paulo apresentou perda de participação, cerca (14 p.p), sugerindo que na região pode estar existindo um comportamento diferente entre os estados quando se analisa o setor industrial.

Para tanto, quando se analisa a indústria de transformação, foco deste estudo, percebe-se que dos quatro estados da região Sudeste, São Paulo e Rio de Janeiro apresentaram perdas de participação, de 8 p.p e 0,35 p.p respectivamente, ao passo que Minas Gerais apresentou ganho de 1,2 p.p. entre 1996 e 2013 e o Espirito Santo praticamente se manteve estável. Esse comportamento entre os estados resultou para a região Sudeste, perda da participação de seu valor adicionado da indústria de transformação ao longo do tempo, e evidencia ser esta região, lócus de estudo, sobre a existência em curso de um processo de desindustrialização com mudança do perfil industrial.

Assim, pela Tabela 02 podemos observar que o setor de serviços ao longo de dezessete anos vem apresentando, paulatinamente, crescimento de sua participação no valor adicionado de todos os estados da região Sudeste, excetuando o estado do Rio de Janeiro, cujo comportamento tem sido declinante.

Tabela 01: Participação percentual dos Valores Adicionados (VAs) da indústria estaduais e regional em relação ao Valor Adicionado (VA) Nacional, 1996-2013 (\%).

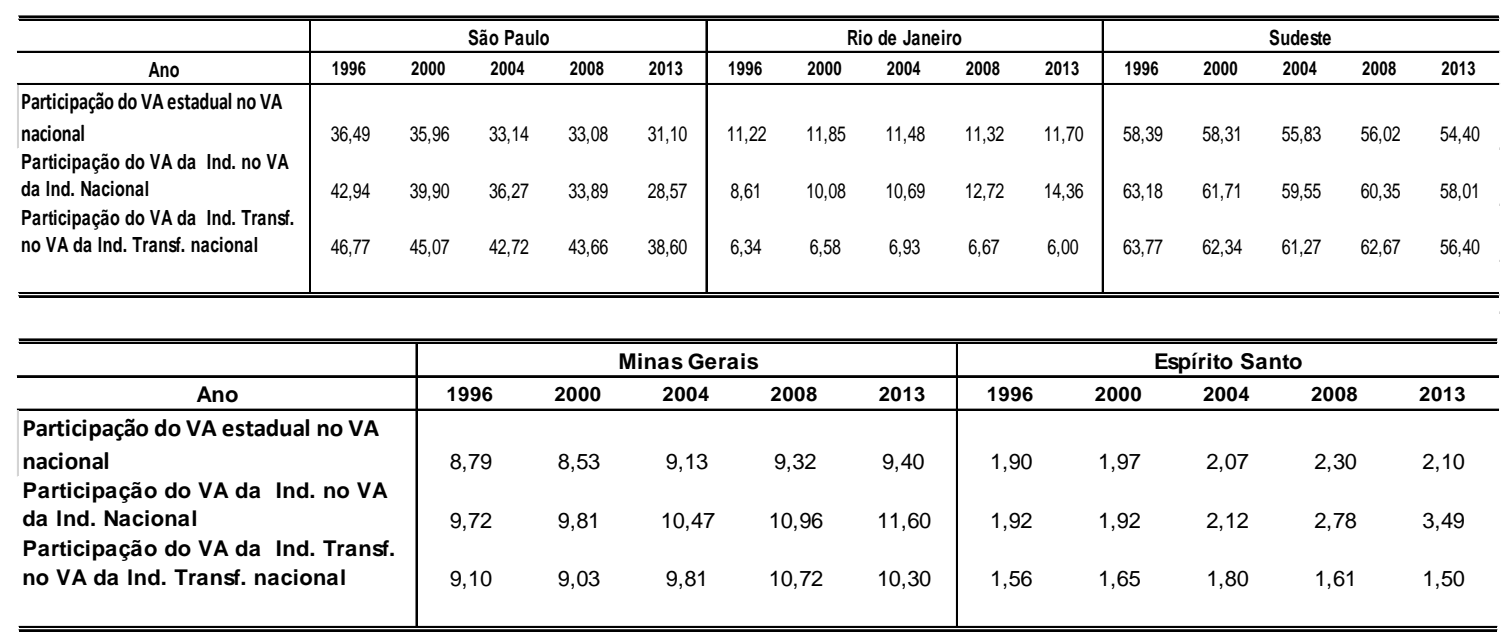

Fonte: IBGE.

Tabela 02: Participação das atividades econômicas no valor adicionado dos estados a preços básicos - Região Sudeste (\%).

\begin{tabular}{|c|c|c|c|c|c|c|c|c|c|c|c|c|c|c|c|c|}
\hline \multicolumn{5}{|c|}{ São Paulo } & \multicolumn{4}{|c|}{ Rio de Janeiro } & \multicolumn{4}{|c|}{ Minas Gerais } & \multicolumn{4}{|c|}{ Espirito Santo } \\
\hline Ano & Agropecuária & Indústria & $\begin{array}{l}\text { Indústria de } \\
\text { transformação }\end{array}$ & Serviços & Agropecuária & Indústria & $\begin{array}{c}\text { Indústria de } \\
\text { transformação }\end{array}$ & Serviços & Agropecuária & Indústria & $\begin{array}{c}\text { Indústria de } \\
\text { transformação }\end{array}$ & Serviços & Agropecuária & Indústria & $\begin{array}{c}\text { Indústria de } \\
\text { transformação }\end{array}$ & Serviços \\
\hline 1996 & 1,33 & 31,38 & 22,09 & 67,29 & 0,71 & 19,94 & 9,49 & 79,36 & 10,58 & 28,66 & 17,36 & 60,77 & 16,06 & 28,32 & 14,82 & 55,63 \\
\hline 2000 & 1,37 & 31,53 & 22,12 & 67,10 & 0,66 & 24,05 & 9,76 & 75,29 & 10,53 & 31,51 & 18,01 & 57,96 & 14,93 & 28,18 & 15,04 & 56,89 \\
\hline 2004 & 2,18 & 33,83 & 25,43 & 63,99 & 0,60 & 28,91 & 11,96 & 70,49 & 9,89 & 33,69 & 20,15 & 56,42 & 9,36 & 32,75 & 17,74 & 57,90 \\
\hline 2008 & 1,45 & 29,52 & 22,66 & 69,03 & 0,44 & 31,56 & 9,87 & 68,01 & 9,47 & 32,17 & 18,75 & 58,36 & 6,84 & 36,03 & 12,46 & 57,13 \\
\hline 2013 & 1,87 & 22,89 & 15,27 & 75,24 & 0,46 & 30,49 & 6,24 & 69,05 & 5,63 & 30,68 & 13,50 & 63,69 & 3,27 & 40,50 & 8,35 & 56,22 \\
\hline
\end{tabular}

Fonte: IBGE

No que tange à indústria de transformação, todos os estados apresentaram queda de sua participação, destacando-se os estados de São Paulo e Espirito Santo com perdas que aproximam 7 p.p. e 
6,5 p.p. respectivamente entre 1996 e 2013. Nesse sentido, a tabela 02 sugere que a indústria de transformação da região Sudeste tem perdido espaço em relação aos demais segmentos industriais, razão pela qual justifica-se aprofundar a investigação, por meio de indicadores específicos, visando compreender o comportamento da dinâmica industrial nos estados de São Paulo, Minas Gerais e Rio de Janeiro.

\section{Comportamento da indústria do estado de São Paulo}

Analisando os Gráficos 01 A e 01 B que evidenciam a evolução por intensidade tecnológica, observa-se que os setores de alta intensidade tecnológica destacaram-se tanto no que se refere ao VBPI, quanto o VTI, principalmente a partir de 2002 e 2003 respectivamente, atingindo em 2013 crescimento aproximado de $127 \%$ para o VBPI e cerca de $71 \%$ para o VTI, ambos em relação ao ano de 1996. Destacaram-se os setores ligados à fabricação de máquinas de escritório e equipamentos de informática, bem como construção, montagem e reparo de aeronaves. Para além disso, o gráfico 01 A (VBPI) evidencia que o estado de São Paulo apresentou de modo geral, salvo algumas oscilações, trajetória positiva para todos os setores ao longo do tempo. De fato, ao se observar tanto o gráfico A (VBPI) e B (VTI) percebe-se que os anos 2002/2003 trata-se de um ponto de inflexão na geração de valor por parte da indústria de transformação, quando praticamente todos os setores por intensidade tecnológica passam a apresentar taxas de crescimento positivas. Ao final do período em análise, a evolução do processo resultou em uma taxa de crescimento dos setores de média alta intensidade tecnológica em cerca de $40 \%$ para o VBPI, consolidando-se como o segundo grupo por intensidade em taxa de crescimento, cujo destaque foi o setor de construção, montagem e reparo de veículos ferroviários e construção, montagem e reparo de veículos automotores. No caso do VTI praticamente todos os setores por intensidade tecnológica apresentaram, ao final do período analisado taxas de crescimento muito próximas, como pode ser observado pelo gráfico $01 \mathrm{~B}$.

Gráfico 01: Evolução por intensidade tecnológica do Valor Bruto da Produção Industrial (VBPI) - A e Valor da Transformação Industrial (VTI) - B - São Paulo, 1996 - 2013, número índice (1996 = 100).

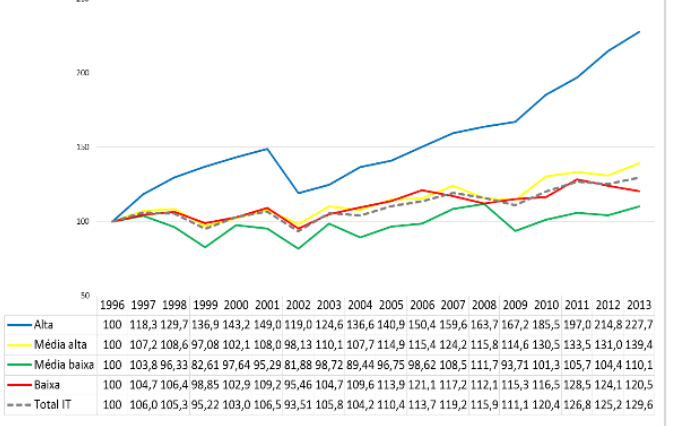

B

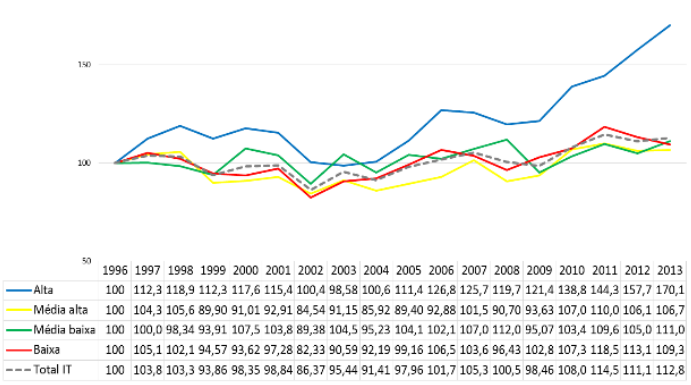

Fonte: Elaboração própria a partir de dados da PIA-IBGE e classificação OCDE (2011).

Nota: Série deflacionada pelo IPEA-OG da FGV a preços de 2013.

Apesar desse comportamento a densidade industrial de São Paulo, apresentada no gráfico 02, apresentou trajetória de queda para todos os setores por intensidade tecnológica. Entre 1996 e 2013 os setores de alta intensidade tecnológica foram aqueles que apresentaram a maior queda da razão VTI/VBPI em cerca de 15,5 p.p., ao passo que os setores de média baixa intensidade apresentaram a menor perda, cerca de 038 p.p.. Entretanto, considerando o ano de 2006/2007 observa-se perda de ritmo da trajetória de perda de densidade, com relativa melhora para os setores de média alta e baixa intensidade tecnológica.

No agregado, a razão VTI/VBPI de São Paulo se manteve praticamente estagnada, entre 2004 e 2013 resultado este, muito influenciado pelo comportamento positivo dos setores de média baixa e baixa intensidade tecnológica que compensaram a queda dos demais agrupamentos. Diante dos resultados deste gráfico e dos gráficos 01 A e 01B infere-se que a indústria paulista apresentou perda de elos em sua 
cadeia produtiva em termos relativos, mas com a uma peculiaridade importante. Mesmo os setores por intensidade tecnológica que apresentaram deterioração do tecido industrial, conseguiram ampliar a geração de valor industrial, sugerindo que aquelas unidades produtivas que se mantiveram ativas, têm empreendido esforços, no sentido de ampliar sua capacidade produtiva e melhorar a produtividade.

Gráfico 02: Razão entre Valor da Transformação Industrial (VTI) e Valor Bruto da Produção Industrial (VBPI) por intensidade tecnológica - São Paulo, 1996 - 2013 (\%).

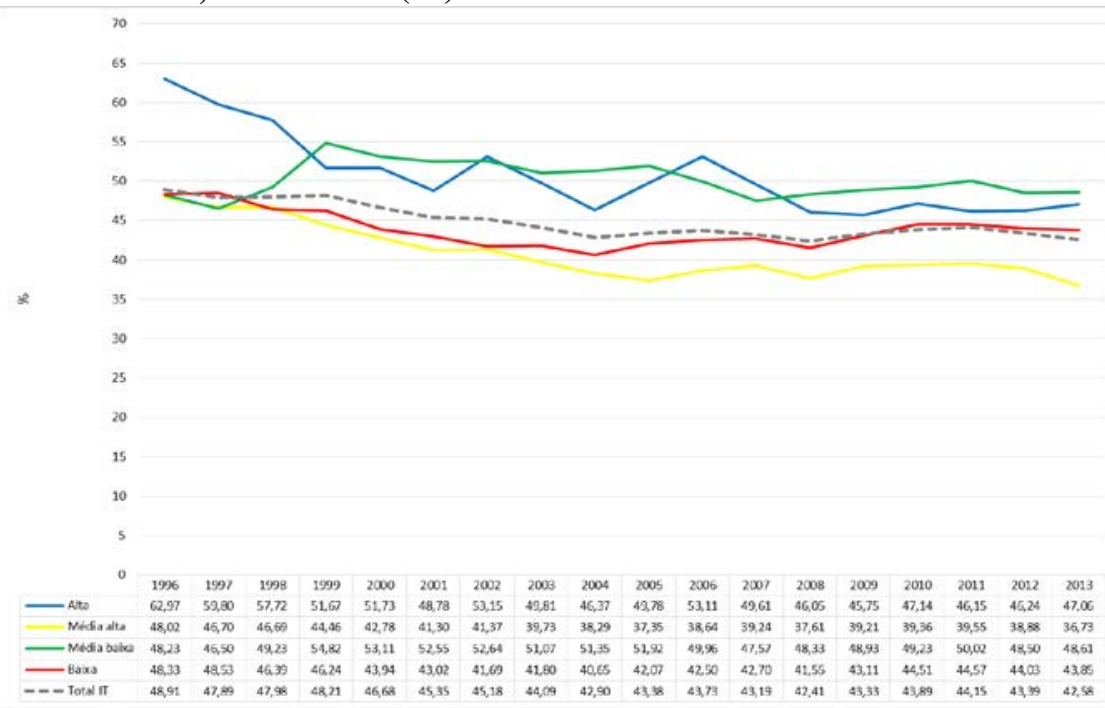

Fonte: Elaboração própria a partir de dados da PIA-IBGE e classificação OCDE (2011). deflacionada pelo IPEA-OG da FGV a preços de 2013.

Do ponto de vista do emprego, como evidencia o Gráfico 03, todos os grupos por intensidade tecnológica apresentaram, a partir de 2003, taxas de crescimento mais significativa, vindo a perder ritmo somente a partir do ano de 2008. Destaca-se que os grupos de maior intensidade tecnológica foram aqueles que apresentam maior sensibilidade quando da crise internacional, e que o grupo de média alta intensidade tecnológica conseguiu ampliar a capacidade de contratação, vindo apresentar taxas similares ao grupo de alta tecnologia em 2013, 54,6\% e 53,9\% respectivamente, em relação ao ano de 1996 . Os setores de alta tecnologia que se destacaram foram os setores de construção, montagem e reparação de aeronaves, fabricação de máquinas para escritório e equipamentos de informática e fabricação de equipamentos de instrumentação médico-hospitalares. No que range aos setores de média alta destacaram-se aqueles ligados à construção, montagem e reparação de veículos ferroviários e máquinas e equipamentos. Cabe destacar que a evolução do emprego apresenta relação com a maturidade dos setores industriais por intensidade tecnológica. Em outros termos, o impacto da elevação do emprego em setores de alta intensidade tecnológica tende a ser maior em função de serem estas unidades produtivas ainda incipientes, o que não ocorre no caso de setores de baixa intensidade tecnológica. 
Gráfico 03: Evolução do emprego por intensidade tecnológica - São Paulo, 1996 - 2014, número índice (1996 =100).

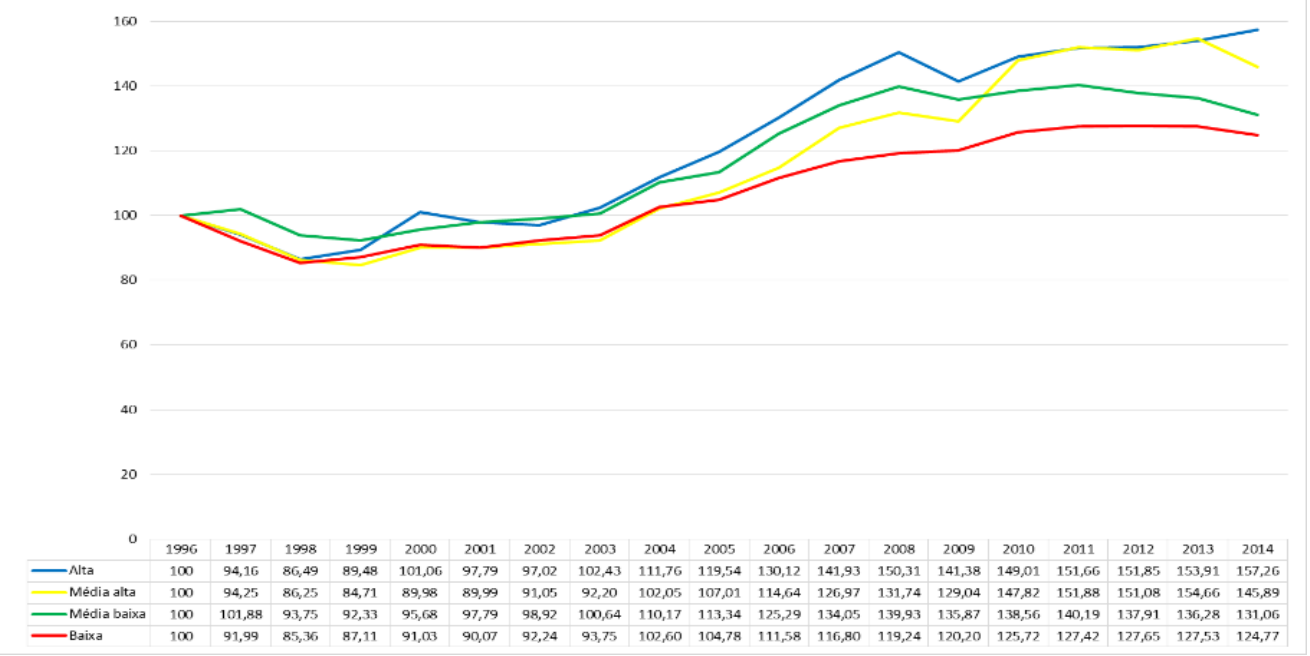

Fonte: RAIS/MTE.

Em síntese, podemos verificar a evolução da indústria do estado de São Paulo por meio do Gráfico 04, que expressa o Índice de Desindustrialização Relativa Regional. Deste modo, existem fortes indícios que a indústria paulista venha sofrendo um forte processo de desindustrialização relativa. Apesar de melhora nos setores de alta intensidade tecnológica até o ano de 1999, evidenciou-se reversão da trajetória de modo que em 2013, São Paulo era responsável por 85\% do desempenho da indústria de transformação de alta intensidade tecnológica. Importante destacar que os setores de média alta e média baixa intensidade tecnológica apresentaram as trajetórias mais negativas sendo que ambos alcançaram em 2013, 76\%. Em outros termos, significa que no período de 1996 - 2013 a indústria de São Paulo teve, em termos relativos $76 \%$ do desempenho da indústria de transformação no que tange aos setores de média alta e média baixa intensidade tecnológica.

Gráfico 04: Índice de Desindustrialização Relativa Regional (DRR) - São Paulo, 1996 - 2013.

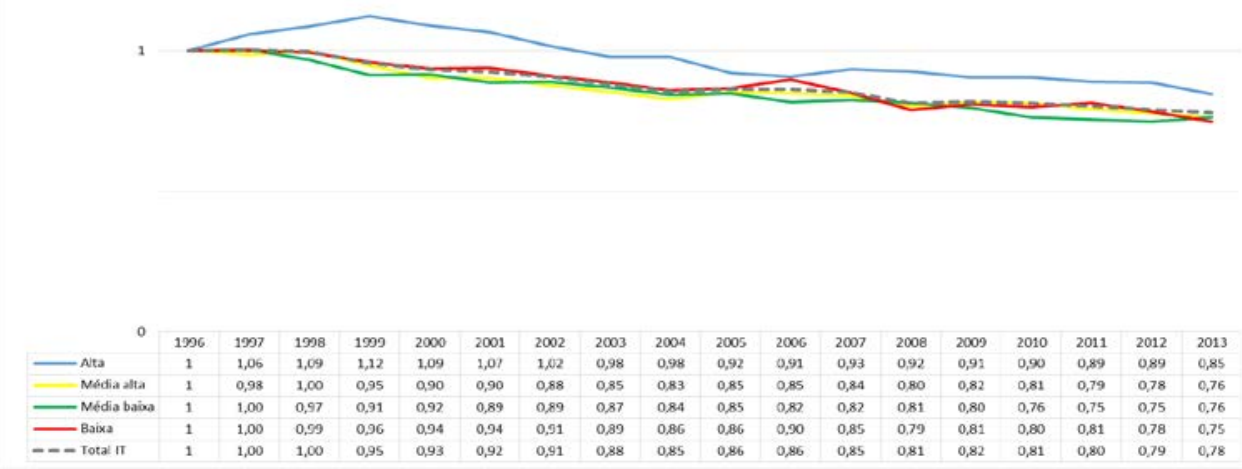

Fonte: PIA-IBGE adaptação da metodologia de Arend (2014).

Quando se analisa a indústria de transformação em sua totalidade, observa-se que a indústria paulista apresentou DRR de 78\%, ou seja, a indústria de São Paulo foi responsável em 2013 por 78\% do desempenho da indústria nacional. Nesse sentido, pode-se considerar que São Paulo apresentou um processo de desindustrialização relativa em todos setores por intensidade tecnológica corroborando o comportamento industrial das últimas décadas. 


\section{Comportamento da indústria do estado do Rio de Janeiro}

Quando se analisa a evolução do VBPI e VTI (Gráficos 05 A e 05 B) percebe-se que os setores de média baixa e média alta intensidade tecnológica, apresentaram taxas de crescimento positivas a partir de 2001, deslocando-se dos demais setores em termos de trajetória. Destacaram-se os setores de construção e reparo de embarcações, fabricação de minerais não metálicos e siderurgia, bem como fabricação e montagem de veículos automotores e fabricação de material elétrico. Os setores de alta e baixa intensidade tecnológica não apresentaram evolução significativa, salvo os setores de baixa intensidade tecnológica, que a partir de 2008, passaram a apresentar taxas positivas, tanto no caso do VBPI quanto do VTI. Analisando o quadro geral da indústria fluminense, esta alcançou uma taxa de crescimento de 62,5\% para o caso do VBPI, e aproximadamente 45\% para o VTI, quando comparados ao ano de 1996. Em outros termos, a indústria do Rio de Janeiro apresentou crescimento positivo de sua indústria de transformação, muito embora os setores que mais contribuíram para esse crescimento foram os setores de média baixa e média alta intensidade tecnológica.

Gráfico 05: Evolução por intensidade tecnológica do Valor Bruto da Produção Industrial (VBPI) - A e Valor da Transformação Industrial (VTI) - B - Rio de Janeiro, 1996 - 2013, número índice (1996 = 100).

A

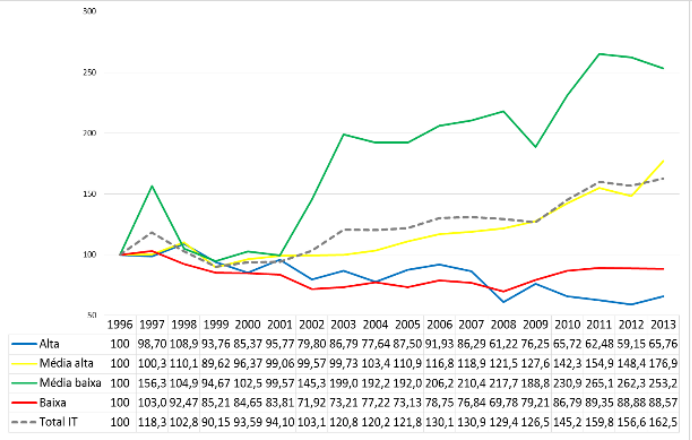

B

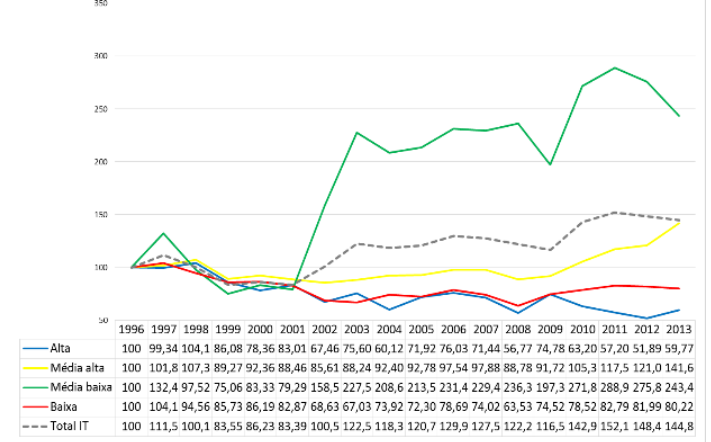

Fonte: Elaboração própria a partir de dados da PIA-IBGE e classificação OCDE (2011).

Nota: Série deflacionada pelo IPEA-OG da FGV a preços de 2013.

Diante disso, como se observa-se no Gráfico 06 (razão VTI/VBPI) que trata da densidade produtiva, observa-se que todos os setores apresentaram trajetória de rareamento entre 1996 e 2013. Entretanto, o comportamento é variado ao longo do período, sendo que a trajetória de deterioração das cadeias produtivas foi mais acentuada durante o período de 1996 até 2002/2003, salvo a oscilação dos setores de média baixa intensidade tecnológica. Entre o período de 2003 até 2007 a trajetória de deterioração das cadeias produtivas foi menos intenso, e a partir de 2007 o comportamento dos grupos por intensidade foi dispare para cada setor. 
Gráfico 06: Razão entre Valor da Transformação Industrial (VTI) e Valor Bruto da Produção Industrial (VBPI) por intensidade tecnológica - Rio de Janeiro, 1996 - 2013 (\%).

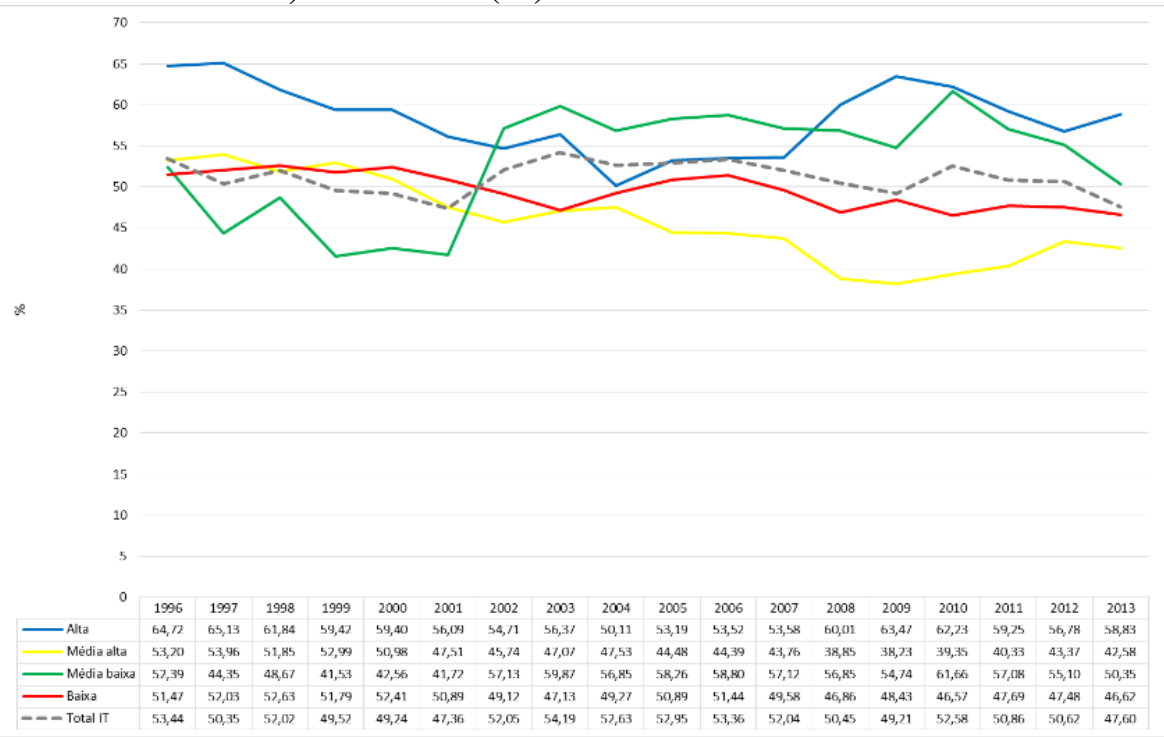

Fonte: Elaboração própria a partir de dados da PIA-IBGE e classificação OCDE (2011).

Nota: Série deflacionada pelo IPEA-OG da FGV a preços de 2013.

Os setores de alta intensidade tecnológica apresentaram melhora, mas este comportamento não se sustentou e já em 2009 apresentou trajetória de queda. Os setores de média alta intensidade tecnológica, após sistemática queda, passou a apresentar trajetória de reestruturação de sua cadeia produtiva. Os demais setores continuaram a apresentar comportamento de deterioração, porém em ritmo bem menos acentuado. Do ponto de visa da indústria de transformação em geral, o indicador sugere que a indústria fluminense apresentou deterioração de sua estrutura industrial, com oscilações pontuais positivas que não conseguiram reverter o a trajetória geral observada.

No que tange ao emprego, analisando o Gráfico 07, observa-se que todos os grupos por intensidade tecnológica apresentaram trajetória de queda do emprego, quando a partir do ano 2000, ocorreu reversão do comportamento das trajetórias específicas. Para tanto, destacaram-se os grupos de média baixa e média alta intensidade tecnológica, que alcançaram em 2014, 64,2\% e 51,8\% respectivamente em relação ao ano de 1996. Mesmo com as oscilações dos anos de crise internacional de 2008/2009, estes grupos mantiveram trajetória positiva com destaque para o grupo de média baixa cuja resposta foi mais favorável. No que se refere aos setores de média baixa intensidade tecnológica destacaram-se aqueles ligados à fabricação de coque, refino de petróleo e construção e reparação de embarcações. Os setores de média alta que se destacaram foram aqueles ligados à fabricação e montagem de veículos automotores e fabricação de máquinas e equipamentos. A despeito desse comportamento, os grupos de baixa e alta intensidade tecnológica não apresentaram evolução significativa como se depreende em relação aos demais estados da região Sudeste. 
Gráfico 07: Evolução do emprego por intensidade tecnológica - Rio de Janeiro, 1996 - 2014, número índice (1996 =100).

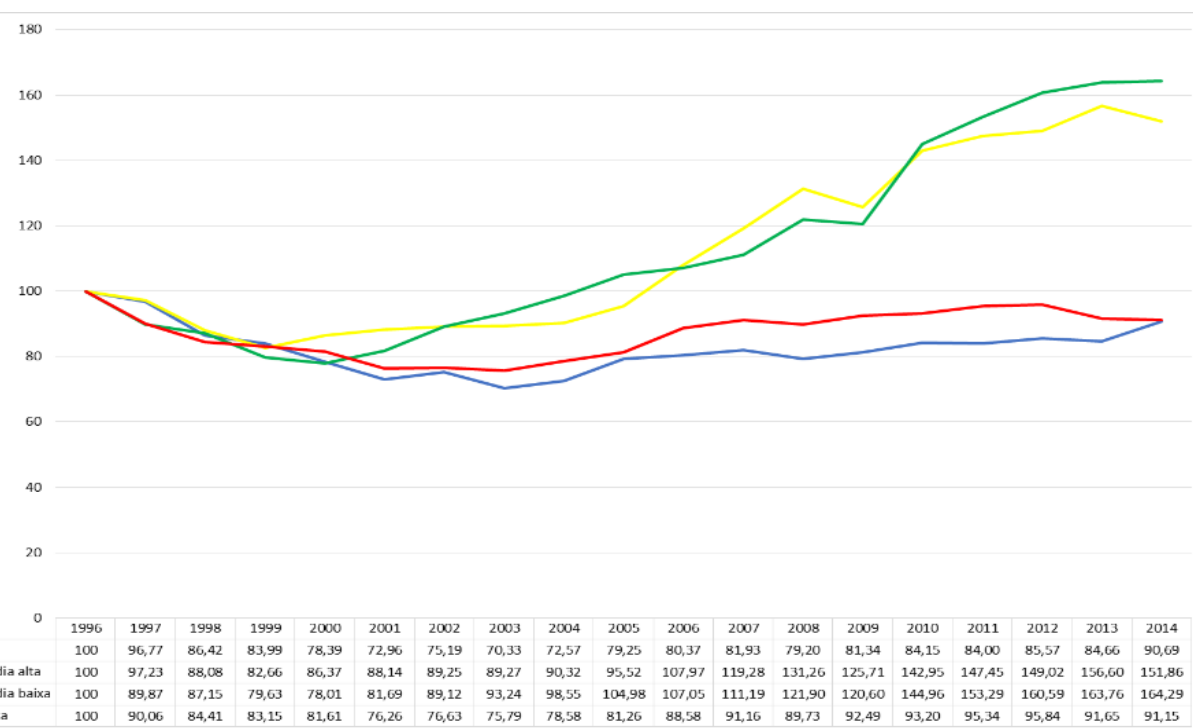

Fonte: RAIS/MTE

Sintetizando, o Gráfico 08 evidencia que a indústria fluminense apresentou comportamento peculiar entre os grupos por intensidade tecnológica ao longo do período em análise, sendo que até o ano de 2001, observou-se trajetória de queda, ou desindustrialização em todos os grupos tecnológicos. A partir de então, o grupo de média baixa intensidade tecnológica inicia um processo de descolamento com trajetória ascendente e manutenção em patamares mais elevados, alcançando em 2013, 75\%. Ou em outros termos, $75 \%$ superior ao desempenho nacional, sugerindo que para este agrupamento ocorreu um processo de industrialização. Os setores de média alta intensidade tecnológica apresentaram reversão da trajetória de desindustrialização a partir de 2003, atingindo em 2013, 97\% do desempenho nacional para este agrupamento.

Gráfico 08: Índice de Desindustrialização Relativa Regional (DRR) - Rio de Janeiro, 1996 - 2013.

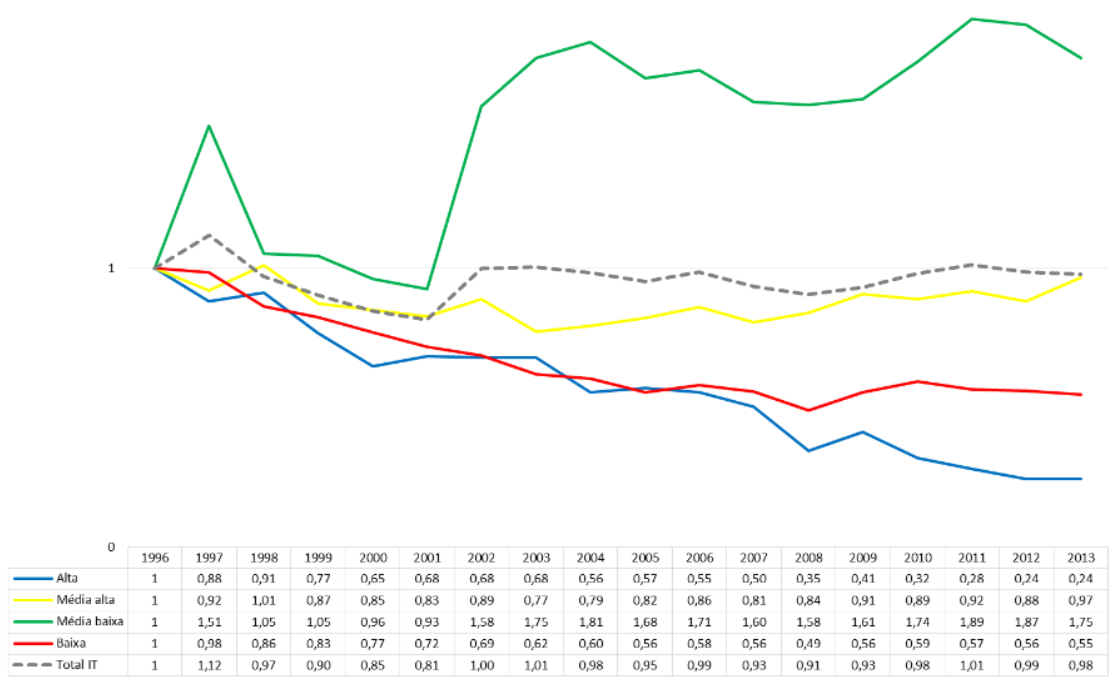

Fonte: PIA-IBGE adaptação da metodologia de Arend (2014).

A despeito disso, os setores de alta e baixa intensidade tecnológica apresentaram trajetória de queda do indicador, sugerindo que estes agrupamentos vem sofrendo de desindustrialização relativa desde 1996, salvo pequenas oscilações no ano de 2008, mas que de modo algum indicou reversão consistente da referida trajetória. Ao se analisar a indústria de transformação como um todo, o indicador sugere que até 2001 a indústria do Rio de Janeiro apresentou comportamento caracterizado por desindustrialização, quando atingiu $81 \%$ do desempenho nacional. A partir de então, observa-se a recuperação da trajetória e 
certa estabilidade até 2013, quando atinge valor próximo a 1, indicando que não houve perda nem ganho relativo. Importante ressaltar que esta estabilidade da indústria de transformação como um todo encontrar respaldo no bom desempenho dos grupo de média baixa intensidade tecnológica e parcialmente nos setores de média alta, cujo comportamento assegurou a estabilidade do indicador em seu agregado.

\section{Comportamento da indústria do estado de Minas Gerais}

Ao se analisar a evolução do VBPI e VTI, Gráficos 08 A e 08 B, observa-se que todos os setores apresentaram taxas de crescimento positivo ao longo do período analisado, destacando os grupos de alta (eixo secundário) e média alta intensidade tecnológica tanto para o VBPI quanto para o VTI. Destacaramse os setores ligados à fabricação de máquinas para escritório e equipamentos de informática, instrumentação médico hospitalares e material eletrônico e comunicação, bem como o setor de construção, montagem e reparo de veículos ferroviários, material elétrico, e maquinas e equipamentos. A trajetória de crescimento foi mais acentuada a partir de 2002 até por volta do ano de 2011, quando alguns setores reduziram o ritmo de crescimento. Importante destacar que nessa trajetória de crescimento os setores de maior valor agregado, excluindo alta intensidade, foram aqueles que sofreram maior oscilação na geração de valor durante o período da crise de 2009.

\section{Gráfico 09: Evolução por intensidade tecnológica do Valor Bruto da Produção Industrial (VBPI) - A e Valor da Transformação Industrial - B - Minas Gerais, 1996 - 2013, número índice (1996 = 100).}

A

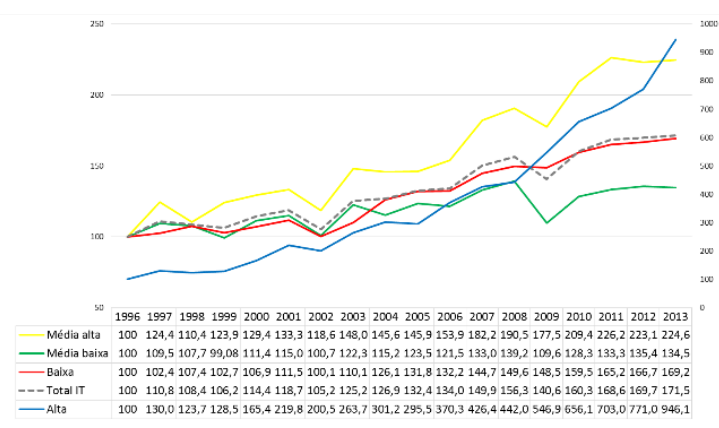

B

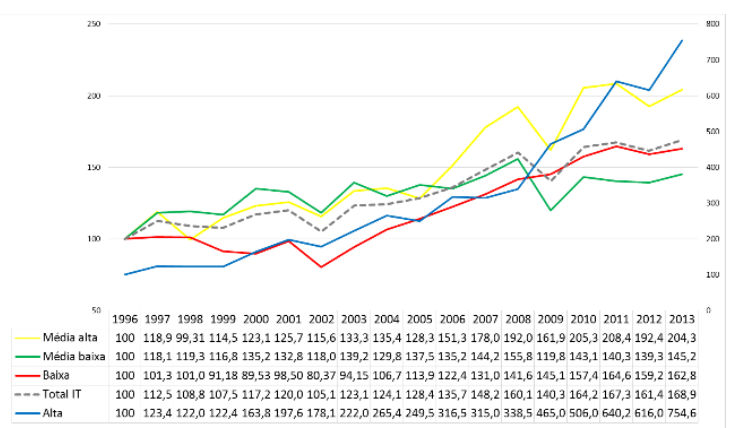

Fonte: Elaboração própria a partir de dados da PIA-IBGE e classificação OCDE (2011). Nota: Série deflacionada pelo IPEA-OG da FGV a preços de 2013.

Ao se analisar a evolução da indústria de transformação como um todo os dados sugerem que a indústria mineira apresentou crescimento na geração de valor adicionado cujos grupos que mais contribuíram para esse crescimento foram aqueles caracterizados pela geração de maior valor agregado, atingindo em 2013, crescimento de 71.5\% e 70\% para o VBPI e VTI em relação a 1996.

Para tanto, ao se analisar o Gráfico 10 que trata da densidade produtiva, observa-se queda em todos os grupos por intensidade tecnológica durante o período analisado, excetuando aqueles ligados à média baixa intensidade tecnológica que apresentou crescimento aproximado de 3,3 p.p. entre 1996 e 2013, e baixa intensidade que a partir de 2002 passou a apresentar reversão da trajetória de deterioração com crescimento de 7 p.p.. Nesse processo destacam-se os setores de alta intensidade tecnológica que durante todo o período analisado apresentou a maior perda de todos os grupos, 12 p.p., sendo que o período de maior queda foi entre 1996 e 2007 (-14,64 p.p.). No agregado, a indústria de transformação apresentou certa estabilidade na razão VTI/VBPI, apesar da queda de -0,6 p.p. ao se analisar todo o período. Entretanto, pequena melhora na trajetória é observada a partir de 2005, muito em função do bom desempenho nos setores de média alta e baixa intensidade tecnológica, que compensaram a queda nos demais grupos. Assim, o indicador sugere que a indústria mineira apresentou certa estabilidade em sua estrutura industrial com melhora mais significativa em setores de baixa intensidade tecnológica e em menor grau média alta intensidade. 
Gráfico 10: Razão entre Valor da Transformação Industrial (VTI) e Valor Bruto da Produção Industrial (VBPI) por intensidade tecnológica - Minas Gerais, 1996 - 2013 (\%).

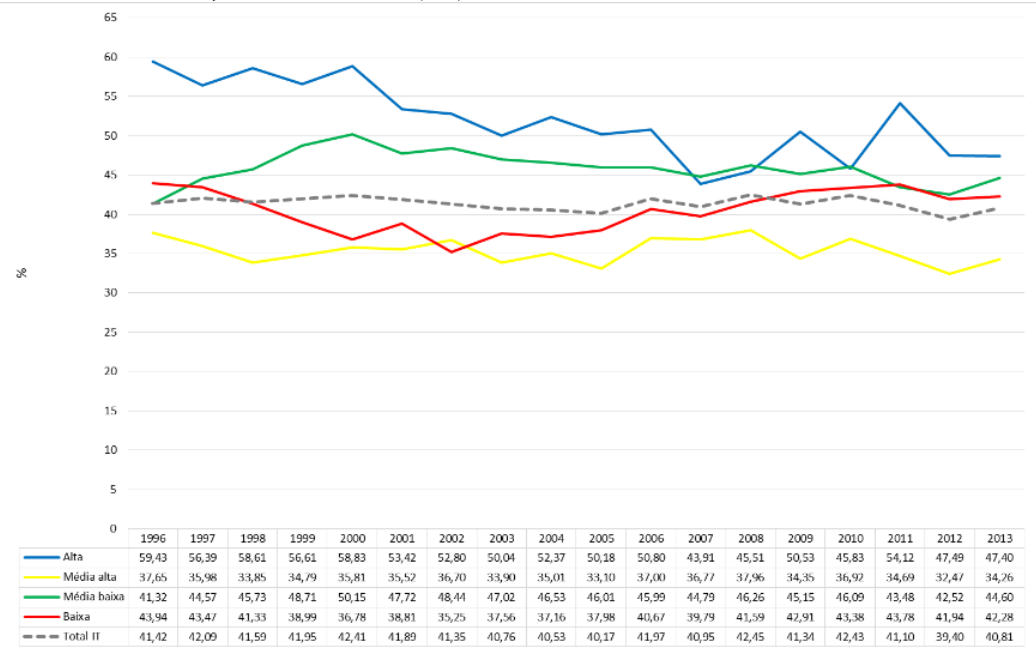

Fonte: Elaboração própria a partir de dados da PIA-IBGE e classificação OCDE (2011). Nota: Série deflacionada pelo IPEA-OG da FGV a preços de 2013.

No tocante ao emprego, conforme evidencia o Gráfico 11, todos os grupos por intensidade tecnológica apresentaram trajetória positiva mais intensa a partir do ano de 2003. Destacaram-se os setores de alta e média alta intensidade tecnológica, 199\% e 127\% de crescimento, respectivamente, no ano de 2014 em relação a 1996, mas com especial atenção a ser dada ao segundo grupo, cujo comportamento ascendente não se sustentou e entrou em declínio a partir de 2012. No que tange ao setores de alta intensidade tecnológica destacaram-se os setores ligados à construção, montagem e reparação de aeronaves, fabricação de produtos farmacêuticos, e fabricação de máquinas para escritório e equipamentos de informática. Com relação à média alta destacaram-se os setores ligados à fabricação de máquinas e equipamentos, fabricação de produtos químicos e fabricação de máquinas, aparelhos e materiais elétricos.

Gráfico 11: Evolução do emprego por intensidade tecnológica - Minas Gerais, 1996 - 2014, número índice (1996 =100).

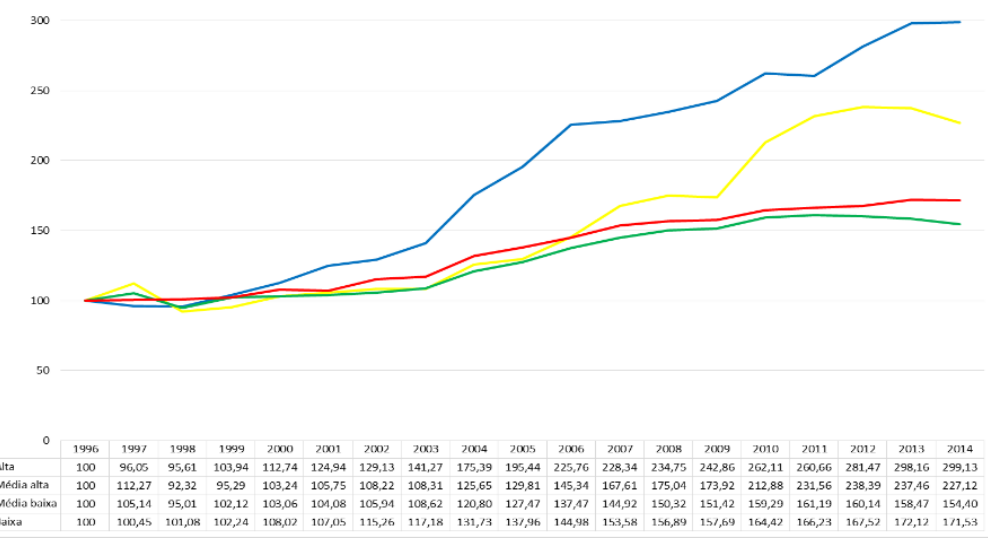

Fonte: RAIS/MTE

Em resumo, o Gráfico 12, sugere que excetuando o grupo de média baixa intensidade tecnológica, todos os demais agrupamentos apresentaram evolução positiva do indicador, de desindustrialização. Nesse contexto, observa-se significativa trajetória positiva em setores de alta intensidade tecnológica, principalmente a partir de 2009, quando alcançou em 2013 um DRR de 250\%. O segundo grupo que apresentou melhor desempenho foi o de média alta intensidade tecnológica, que a partir de 2005 apresentou comportamento mais positivo, com $23 \%$ de desempenho superior comparativamente ao mesmo grupo em relação ao restante do Brasil. 
Gráfico 12: Índice de Desindustrialização Relativa Regional (DRR) - Minas Gerais, 1996 - 2013.

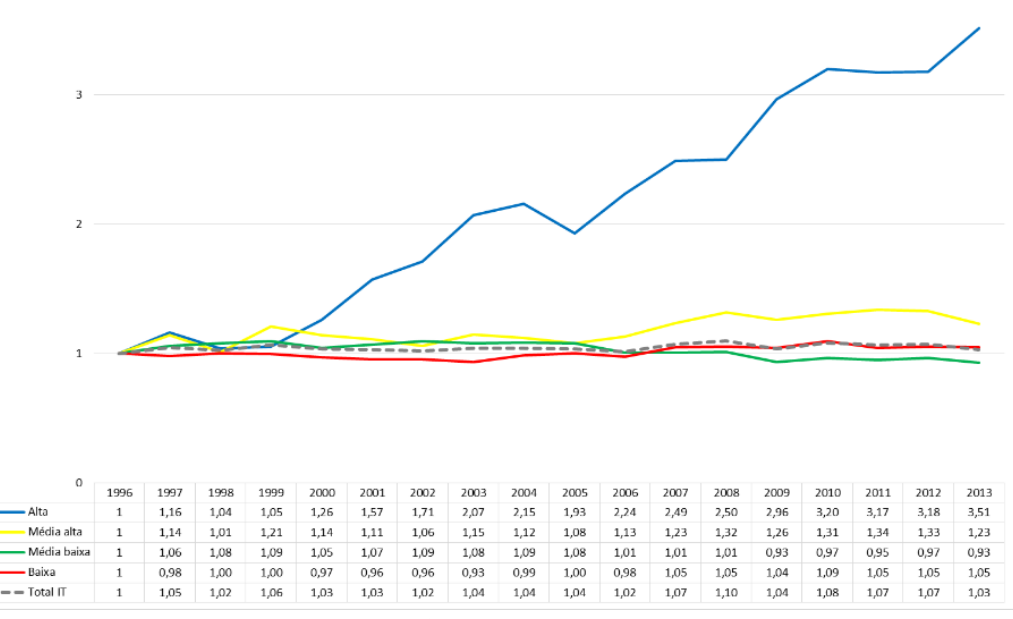

Fonte: PIA-IBGE adaptação da metodologia de Arend (2014).

Os setores de baixa intensidade tecnológica apresentaram desempenho praticamente estagnado ao longo de todo o período analisado e aqueles ligados à média baixa intensidade tecnológica apresentaram comportamento que pode ser qualificado como em processo de desindustrialização dado que a partir de 2006 engendrou processo de queda do indicador quando atingiu em 2013 DRR de 93\%. Avaliando a indústria de transformação em sua totalidade observa-se que ao longo de todo o período analisado a indústria mineira apresentou desempenho ligeiramente positivo, sugerindo que a mesma apresentou uma trajetória de industrialização em relação ao restante do pais, uma vez que atingiu em 2013, DRR de 3\%, ou em outros termos, a indústria mineira apresentou desempenho superior de $3 \%$ em relação ao restante da indústria brasileira.

\section{Avaliação Agregada da Indústria da Região Sudeste: mudança estrutural em curso}

Assim, pode-se sintetizar os indicadores para os estados da região Sudeste através da Tabela 03 em três periodizações de análise, a saber: 1996 a 2002, 2003 a 2009 e 2010 a 2013. Desta feita, durante o primeiro período o VBPI, VTI para o estado São Paulo e Rio de Janeiro, apresentou trajetória de crescimento negativa para todos os setores por intensidade tecnológica, excetuando aqueles de mais alto valor agregado, para a indústria paulista e de média baixa intensidade para o Rio de Janeiro. No que tange ao emprego ambos os estados apresentaram taxas negativas para todos os setores. A indústria mineira, no que tange ao VBPI, VTI e o emprego, apresentou comportamento diferenciado em relação aos demais estados, com pequeno crescimento, ou crescimento vegetativo em todos os grupos por intensidade tecnológica, excetuando aqueles de maior valor agregado. 
Tabela 03: Sumário do comportamento da indústria por estado e região Sudeste 1996-2013.

\begin{tabular}{|c|c|c|c|c|c|c|c|c|c|c|c|c|c|c|c|c|}
\hline & & \multicolumn{3}{|c|}{ VTI } & \multicolumn{3}{|c|}{ VBPI } & \multicolumn{3}{|c|}{ VTI-VBPI } & \multicolumn{3}{|c|}{ EMP } & \multicolumn{3}{|c|}{ DRR } \\
\hline & & 1996 & 2003 & 2010 & 1996 & 2003 & 2010 & 1996 & 2003 & 2010 & 1996 & 2003 & 2010 & 1996 & 2003 & 2010 \\
\hline \multirow{5}{*}{$\begin{array}{l}\mathscr{2} \\
\stackrel{2}{ } \\
\text { Dू } \\
\text { co }\end{array}$} & Alta & $+/-$ & + & ++ & $+/-$ & + & ++ & - & - & $+/-$ & - & + & $+/-$ & $+/-$ & - & - \\
\hline & Média alta & - & $+/-$ & + & - & $+/-$ & + & - & - & - & - & + & + & - & - & - \\
\hline & Média baixa & - & - & - & - & - & - & $+/-$ & - & $+/-$ & - & + & - & - & - & - \\
\hline & \begin{tabular}{|l|} 
Baixa \\
\end{tabular} & - & $+/-$ & + & - & $+/-$ & $+/-$ & - & $+/-$ & $+/-$ & - & + & $+/-$ & - & - & - \\
\hline & Total & - & $+/-$ & + & - & $+/-$ & + & - & - & $+/-$ & - & + & $+/-$ & - & - & - \\
\hline
\end{tabular}

\begin{tabular}{|c|c|c|c|c|c|c|c|c|c|c|c|c|c|c|c|c|}
\hline \multirow{5}{*}{ 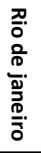 } & Alta & - & - & $+/-$ & - & - & $+/-$ & - & $+/-$ & - & - & $+/-$ & $+/-$ & - & - & - \\
\hline & Média alta & - & $+/-$ & ++ & - & + & ++ & - & - & + & - & + & + & - & $+/-$ & + \\
\hline & Média baixa & + & - & $+/-$ & + & - & + & $+/-$ & - & - & - & + & ++ & + & - & + \\
\hline & Baixa & - & $+/-$ & + & - & $+/-$ & + & - & $+/-$ & - & - & + & $+/-$ & - & - & + \\
\hline & Total & $+/-$ & - & + & $+/-$ & $+/-$ & + & - & - & - & - & + & + & - & - & $+/-$ \\
\hline
\end{tabular}

\begin{tabular}{|c|c|c|c|c|c|c|c|c|c|c|c|c|c|c|c|c|}
\hline \multirow{5}{*}{ 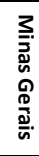 } & Alta & ++ & ++ & ++ & ++ & ++ & ++ & - & $+/-$ & $+/-$ & + & + & + & + & + & ++ \\
\hline & Média alta & $+/-$ & + & $+/-$ & $+/-$ & + & + & - & $+/-$ & - & $+/-$ & + & ++ & $+/-$ & $+/-$ & - \\
\hline & Média baixa & $+/-$ & - & - & $+/-$ & - & - & $+/-$ & - & - & $+/-$ & + & $+/-$ & $+/-$ & - & - \\
\hline & Baixa & - & + & + & $+/-$ & + & + & - & $+/-$ & $+/-$ & $+/-$ & + & + & - & $+/-$ & - \\
\hline & Total & $+/-$ & $+/-$ & $+/-$ & $+/-$ & $+/-$ & + & - & $+/-$ & - & $+/-$ & + & + & $+/-$ & - & - \\
\hline \multirow{5}{*}{$\begin{array}{l}\check{c} \\
\frac{0}{0} \\
\frac{0}{0}\end{array}$} & Alta & - & $+/-$ & ++ & $+/-$ & + & ++ & - & - & $+/-$ & - & + & $+1-$ & - & - & - \\
\hline & Média alta & - & $+/-$ & + & $+/-$ & $+/-$ & + & - & - & - & - & + & + & - & - & - \\
\hline & Média baixa & $+/-$ & - & - & - & - & $+/-$ & $+/-$ & - & - & - & + & $+/-$ & - & - & - \\
\hline & Baixa & - & $+/-$ & + & - & $+/-$ & + & - & $+/-$ & $+/-$ & - & + & $+/-$ & - & - & - \\
\hline & Total & - & $+/-$ & + & - & $+/-$ & + & - & - & - & - & + & + & - & - & - \\
\hline
\end{tabular}

Fonte: Elaboração própria usando taxa média de crescimento anual, a partir PIA/IBGE, SECEX, RAIS, onde (-) crescimento negativo, (+/-) crescimento "vegetativo" entre $0 \%$ e $3 \%$ incluindo este, $(+)$ crescimento positivo entre $3 \%$ e $10 \%$ incluindo este, $\mathbf{e}(++)$ crescimento maior que $10 \%$.

No segundo período que compreende os anos de 2003 a 2009 correspondeu a fase em que a economia brasileira apresentou taxas expressivas de crescimento econômico, refletindo por consequência no crescimento do VBPI, VTI e no emprego de forma positiva, porém não de forma extremamente significativa. Todos os setores apresentaram crescimento, destacando os setores de maior valor agregado como em Minas Gerais e São Paulo, excetuando o grupo de média baixa intensidade nos três estados do Sudeste, cujo comportamento já refletia a crise internacional. No terceiro período, 2010 a 2013, que compreendeu a fase marcada por políticas anticíclicas, observa-se o comportamento positivo por parte do VBPI, VTI e do emprego, porém em um ritmo menos intenso.

Analisando a razão VTI/VBPI e o DRR, constata-se que o período de 1996 a 2002 foi marcado pela deterioração da estrutura industrial nos três estados em todos os grupos por intensidade tecnológica, sugerindo que aqueles setores ligados a média baixa intensidade conseguiram apresentar comportamento mais satisfatório. Durante o período de 2003 a 2009, ocorreu pequena melhora na trajetória de deterioração da estrutura industrial, porém grupos por intensidade específicos, notadamente naqueles de baixa intensidade tecnológica, para São Paulo e Rio de Janeiro e alta no caso de Minas Gerais. Por fim, no último período, constatou-se que a estrutura industrial manteve o comportamento da fase anterior com pequena melhora em São Paulo. $\mathrm{O}$ indicador DRR quando contraposto à razão VTI/VBPI sugeriu que o estado de São Paulo apresentou comportamento marcado pela desindustrialização em todos os períodos analisados, ao passo que para Minas Gerais, sugeriu a existência de uma trajetória mais favorável quando se analisa por grupo tecnológico.

Assim posto, para a região Sudeste, os indicadores sugeriram a existência de um processo de desindustrialização quando se analisa a indústria de transformação como um todo, com tendência a especialização em setores de menor valor agregado. Essa evidência pode ser corroborada por meio do Gráfico 13, onde o estado de São Paulo seguiu sua trajetória de desindustrialização ao longo de todo o período analisado, ao passo que Minas Gerais e o Rio de Janeiro apresentaram comportamentos diferenciados. 
Gráfico 13: Índice de Desindustrialização Relativa Regional (DRR) - Sudeste, 1996 - 2013.

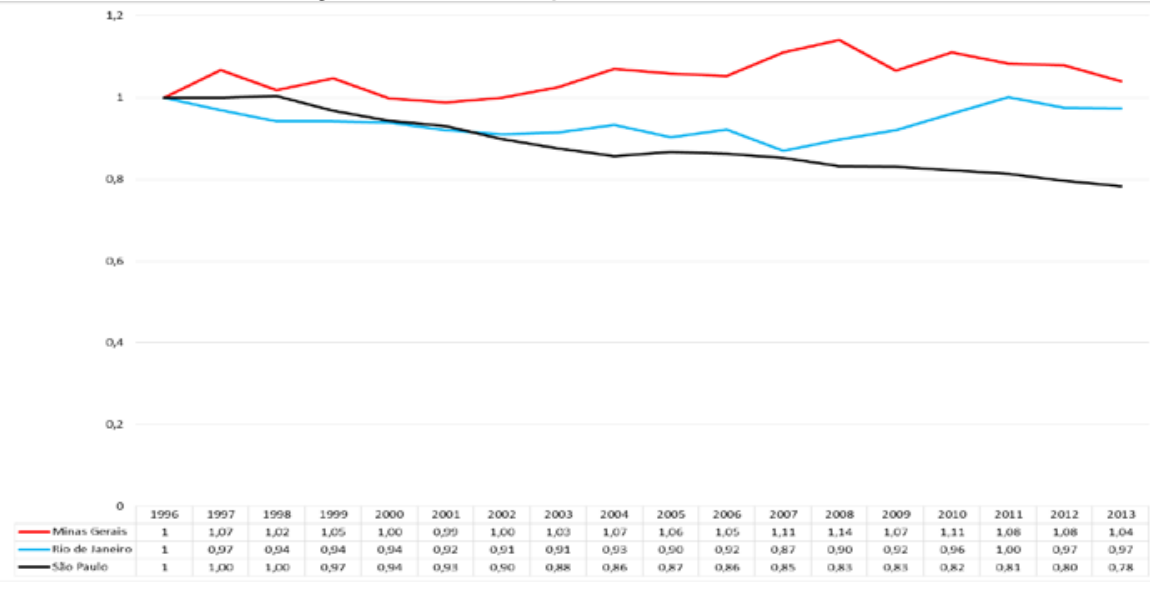

Fonte: PIA-IBGE adaptação da metodologia de Arend (2014).

A indústria mineira reverteu sua trajetória a partir de 2001 e atingiu pico em 2008 quando foi responsável por $14 \%$ do desempenho industrial em relação ao Brasil. O Rio de Janeiro reverteu sua trajetória a partir de 2007, e atingiu pico em 2011, sugerindo que a indústria fluminense estabilizou seu processo de desindustrialização. Desta feita, os três estados analisados apresentaram comportamento diferenciado de sua indústria ao longo de dezessete anos, sendo que o estado de Minas Gerais foi a unidade federativa que apresentou melhor desempenho. Por fim, importante ressaltar que a partir do ano de 2004, o comportamento da indústria de Minas Gerais e Rio de Janeiro apresentou trajetória positiva, o que possivelmente pode ser explicado pelas políticas anticíclicas e incentivos industriais que foram implementadas a partir de então.

\section{Conclusão Geral}

O presente artigo apontou que os três estados apresentaram comportamentos específicos ao longo do período analisado. No caso do estado de São Paulo, evidenciou-se que todos os grupos por intensidade tecnológica apresentaram trajetória de queda da razão VTI/VBPI ao longo do período analisado, muito embora a geração de valor em setores de alta e média alta intensidade tecnológica apresentaram trajetória positiva.

No caso do Rio de Janeiro, os dados sugeriram recuperação do tecido industrial fluminense (VTI/VBPI) principalmente para o grupo de alta e média baixa intensidade tecnológica, apesar deste último ter apresentado evolução mais significativa, muito em função de setores ligados ao petróleo e equipamentos complementares, resultando em VBPI e VTI mais expressivos durante os dezessete anos analisados.

Em Minas Gerais, observou-se um comportamento industrial mais peculiar, marcado pela evolução positiva do valor gerado em setores de alta e média alta intensidade tecnológica com recuperação da estrutura produtiva, principalmente no que se refere aos setores de baixa intensidade tecnológica a partir de 2007. Apesar disso, a indústria mineira apresentou perdas de elos na cadeia produtiva, o que mostra que o processo de desindustrialização manteve-se em curso em determinados períodos.

O indicador de DRR apontou que os estados de Minas Gerais e Rio de Janeiro apresentaram melhor performance principalmente a partir de 2007, e que a indústria paulista apresentou processo de desindustrialização relativa durante todo o período analisado. Portanto, pode-se considerar que a região Sudeste apresentou trajetória de mudança estrutural, no sentido de uma indústria de baixa intensidade tecnológica para média baixa, com destaque para o Rio de Janeiro, e média alta intensidade tecnológica, para São Paulo e Minas Gerais. Por fim, os dados corroboraram a proposição de Comin (2009) ao colocar que a indústria de transformação não parou de crescer, e até mesmo mostrou um dinamismo elevado em 
alguns dos anos mais recentes, muito embora esse comportamento não tenha estancado o processo de esvaziamento produtivo. Assim, constatou-se que os estados da região Sudeste apresentaram comportamento diferenciado e com desindustrialização relativa em setores de maior intensidade tecnológica ao longo de dezessete anos.

\section{Referências Bibliográficas}

AREND, M. A industrialização do Brasil ante a nova divisão internacional do trabalho. In: IPEA. Presente e Futuro: desafios ao desenvolvimentismo brasileiro. IPEA, 2014.

BAZEN, S.; THIRLWALL, A. De-industrialisation: Studies in the UK economy. 1989.

BLACKABY, F. T. (1978). De-industrialisation. Heinemann Educational Books. London.

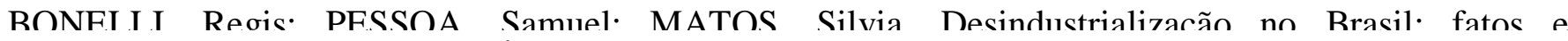
internretacãn $\cap$ futurn da indístria no Brasil: desindustrialização em debate. Rio de Janeiro: Civilização Brasileira, p. 201-225, 2013.

RRF.SSF.R-PF.RFIRA I. C. • MARCONI N. Existe Doença Holandesa no Brasil? IV Fórum de Economia da Fundação Getúlio Vargas. 2008.

BRESSER-PEREIRA, Luiz Carlos. Maldição dos recursos naturais. Folha de S. Paulo, v. 6, n. 06, 2005.

CAIRNCROSS, Alec. (1978). What is De-industrialisation? In: Blackaby, F. (ed.), Deindustrialisation. Heinemann Educational Books. London.

CARNEIRO, R. Impasses do desenvolvimento brasileiro: a questão produtiva. Textos para Discussão, Campinas: IE/UNICAMP, n. 153, nov. 2008.

COMIN A A desindıstrializarão truncada:: nersnectivas dn desenvolvimento esnnômirn hracileirn 20ก9 $271 \mathrm{f}$ Tese (Doutorado) - Curso de Economia, Economia, Universidade Estadual de Campinas, Campinas, 2009.

FEIJÓ, C. OLIVEIRA, D. "Mudanças estruturais na economia brasileira e seus impactos sobre a evolução da produtividade na indústria de transformação pós- 1990” In: AZEVEDO, A.F; FEIJO, C; CORONEL, D.A. (orgs). A Desindustrialização Brasileira. Editora Unisinos, São Leopoldo. 2013.

FFRR A7. I $\Gamma$ · KITPFFR $\Pi$ - HACIIFNAITFR, L.. Made in Brazil: desafios competitivos para a indústria. Rio de janeiro: Campus, p. 386, 1995.

FURTADO, C. Desenvolvimento e subdesenvolvimento. Rio de Janeiro: Fundo de Cultura, 1961.

KALDOR, N. Causes of the slow rate of economic growth of the United Kingdom. Cambridge University Press. 1966.

I.API.ANF. M - SARTI F Prnmetelı Arorrentadn n Rrasil na indústria mundial no início do século XXI. Política Econômica em Foco, n. 7, p. 271-291, 2006.

LOURES, R.R; OREIRO, J.L; PASSOS, C.A.K. "Desindustrialização: a crônica da servidão consentida". Economia e Tecnologia, Ano 2, Vol. 4, 2006.

MORC.F.IRO Paıln César Mecindıctrializarãn na ernnnmia hracileira nn neríndn 7.000-2011: abordagens e indicadores. Coleção PROPG Digital (UNESP), p. 301 p.: il., gráfs., tabs., 2012.

NRFIRO Incé I.uic FF.IIÓ C.armem A nesindıctrializarãn rnnreituação, causas, efeitos e o caso brasileiro. Revista de economia política, v. 30, n. 2, p. 219-232, 2010.

PALMA, José Gabriel (2005). Quatro fontes de “desindustrialização" e um novo conceito de "doença holandesa". Trabalho apresentado na Conferência de Industrialização, Desindustrialização e Desenvolvimento, organizada pela FIESP e IEDI. Centro Cultural da FIESP, 28 de Agosto de 2005.

PALMA, José Gabriel (2008). "De-industrialization”, “premature” de-industrialization and the Dutch Disease. In: Durlauf, S. N.; Blume, L. E. (org.), The New Palgrave Dictionary of Economics. Second Edition. Palgrave Macmillan. 
PEREIRA, W. M. Mudança Estrutural e Desindustrialização na Região do Sul do Brasil: um estudo comparado. 227 f. Dissertação (Mestrado) - Curso de Economia, Economia, Universidade Federal de Santa Catarina, Florianópolis, 2016.

PF́RF.7. rarlnta Rovolurinnes ternolńoicas v ranital financiero: la dinámica de las grandes burbujas financieras y las épocas de bonanza. Siglo XXI, 2004.

ROWTHORN, R. e COUTTS, K. Commentary: Deindustrialisation and the balance of payments in advanced economies. Cambridge Journal of Economics. vol. 28, no. 5, 767-790. 2004.

ROWTHORN, R.; RAMASWAMY, R. Growth, trade, and deindustrialization. IMF Staff papers, p. 1841, 1999.

SARTI F - HIRATIIKA $\Gamma$. Desenvolvimento industrial no Brasil: oportunidades e desafios futuros. Campinas: IE. Unicamp, 2011.

SILVA, H. C. O processo de desindustrializacão: uma avaliacão sob a perspectiva da economia brasileira (1990-2010). 157 f. Dissertação (Mestrado) - Curso de Economia, Economia, Universidade Federal de Santa Catarina, Florianópolis, 2012.

SINGH, A. (1977). UK Industry and the World Economy: A case of Deindustrialization? Cambridge Journal of Economics. Vol. 1, $\mathrm{n}^{\circ} 2$, june.

TORRES, Ricardo Lobato; DA SILVA, Henrique Cavalieri. Uma crítica aos indicadores usuais de desindustrialização no Brasil. Revista de Economia Política, v. 35, p. 4, 2015.

THIRWALL, A.P. The nature of economic growth.Edward Elgar: Aldershot. 2002

TREGENNA. Fiona. Characterising deindustrialisation: An analvsis of changes in manufacturing employment and output internationally. Cambridge Journal of Economics, v. 33, n. 3, p. 433-466, 2009.

UNCTAD. World Development Report. Genebra, 2003. 